\title{
ALGUNAS REFLEXIONES SOBRE LAS PRÁCTICAS ESCRITURARIAS EN LOS ANDES COLONIALES $(\text { SIGLO XVII) })^{1}$
}

\author{
SOME REFLECTIONS ON SCRIPTURAL PRACTICES \\ IN THE COLONIAL ANDES (CENTURY XVII)
}

\section{PAULA MARTÍNEZ SAGREDO²}

\section{RESUMEN}

A partir del análisis de un corpus documental colonial se revisan algunas prácticas escriturarias de la zona centro sur andina de fines del siglo XVI y comienzos del XVII. A través de este corpus documental es posible establecer que existieron modalidades semejantes a los talleres medievales de escritura, pero que en la coyuntura andina se especializaron en el rescate de las tradiciones prehispánicas y que, entre otro tipo de instituciones, permiten explicar el uso de la escritura por parte de algunos indígenas que posteriormente se consolidarían en la tradición literaria hispanoamericana, como Guamán Poma o Pachacuti.

Palabras clave: Escritura, Francisco de Ávila, volumen 3169 BNM, Andes coloniales.

\section{ABSTRACT}

From a colonial documentary corpus we analyse some scriptural practices of the south central Andes during the late sixteenth and early seventeenth centuries. Through this documentary corpus, it can be established that methods similar to those used in medieval writing workshops were used; nevertheless, in the Andean situation there was a specialization in rescuing pre-Hispanic traditions that, together with other institutions, could explain the use of writing on the part of some natives who later would become consolidated in the Latin American literary tradition, such as Guaman Poma or Pachacuti.

Keywords: Writing, Francisco de Avila, volume 3169 BNM, colonial Andes.

Recibido: 03.02.11. Aceptado: 16.06.11.

${ }^{1}$ Este artículo forma parte del proyecto Fondecyt 1090110 "Discursos andinos coloniales: soportes, confluencias y transformaciones”. E-mail: pmartinez@dhas.cl

${ }^{2}$ Magíster en Lingüística Hispánica (Universidad de Chile), Doctor (c) en Literatura. Universidad de Chile. Docente Universidad Autónoma de Chile, Escuela de Fonoaudiología, Facultad de Ciencias de la Salud. Santiago, Chile. E-mail: paula.martinez@docentes.uautonoma.cl 


\section{EL VOLUMEN 3169 DE LA BNM. AUTORES Y ESCRIBAS}

$\mathrm{H}^{\mathrm{N}}$ el volumen 3169 de la Biblioteca Nacional de Madrid se encuentran Cencuadernados los siguientes documentos ${ }^{3}$ :

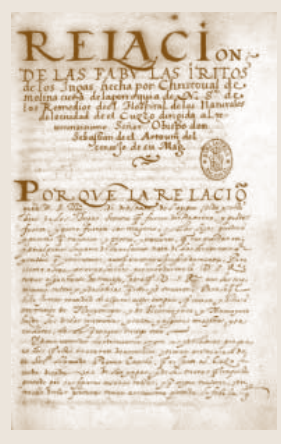

1) Relación de las fábulas y ritos de los Yngas hechas por Christoval de Molina cura de la parroquia de nuestra señora de los Remedios de el Hospital de los Naturales de la ciudad de el Cuzco dirigida al reverendíssimo Señor Obispo don Sebastián de el Artaum del consejo de su Magestad, Fojas 2r a 36v.

El documento de Molina es copia ${ }^{4}$.

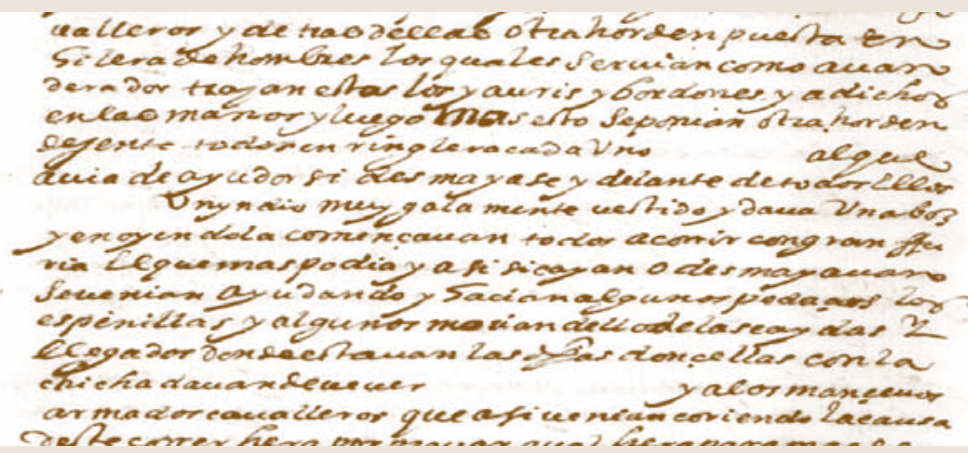

Imagen 1, foja 23v.

$\mathrm{Al}$ respecto, son destacables las consideraciones hechas por Urbano y Duviols (1989: 43) en su edición de esta Relación. Según los datos aportados por ellos, el manuscrito de Molina aparece encuadernado en el volumen $1173^{5}$ de la Biblioteca Nacional de Madrid, junto con otros papeles,

entre los cuales aparece el Tratado de Juan Polo de Ondegardo sobre el linaje de los incas y el manuscrito de Huarochirí, compilado por Francisco de Ávila. La letra de la Relación de Molina es del siglo XVII y similar a la empleada en el manuscrito de Ávila. Es posible que esta copia de Molina pertenezca a los papeles utilizados por Francisco de Ávila para

\footnotetext{
${ }^{3}$ De todos los documentos, sólo el Manuscrito de Huarochirí tiene rúbrica al final. Taylor (1987) se pregunta si es la rúbrica del escribano.

${ }^{4}$ Así, en la copia de Molina encontramos huellas de copia en las fojas 13r, 16r, 16v, 17v, 18v, 22r, 23r, 23v, 26r, 26v, 27r, 30r, 31r (?), 31v, 34r.

${ }^{5}$ Evidentemente se trata del mismo volumen cuya numeración ha cambiado desde 1933, cuando Julián Paz realizó su Catálogo de manuscritos de América.
} 
la elaboración de sus tratados sobre idolatrías de indios peruanos o sus sermones antiidolátricos"6.

A pesar de lo que señalan Urbano y Duviols, quienes distinguen una sola letra, identificamos en esta Relación al menos tres grafías distintas: la del título -que probablemente sea la de Ávila-, y dos más que se turnan en la redacción del manuscrito. Con respecto a las afirmaciones de estos autores, tampoco consideramos que la letra sea la misma que la del Tratado y relación.

Tras [l]ado de un cartapacio a manera de borrador que quedó en los papeles de el licenciado Polo de Ondegardo cerca de el linage de los Yngas y como conquistaron, fojas $37 \mathrm{r}$ a $60 \mathrm{v}$. Este Tra[s]lado es una descuidada copia ${ }^{7}$ de Notables daños de no guardar a los indios sus fueros.

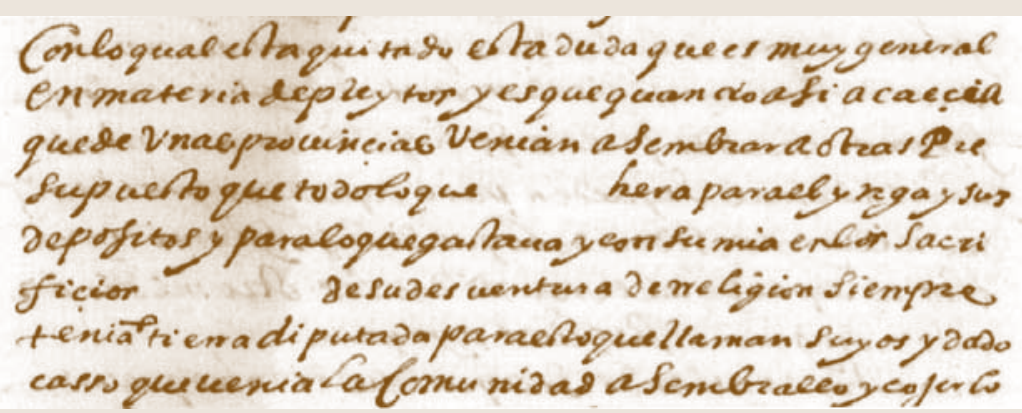

Imagen 2, foja 49r.

Creemos que parte de la confusa tradición de este manuscrito se originó con la edición de Urteaga y Romero, donde aparece titulada como Verdadero y legítimo dominio de los reyes de España sobre el Perú. Identificamos en este manuscrito las mismas tres letras que en el anterior.

Gerald Taylor (1980: 5-6) señala el vínculo que existió entre Polo de Ondegardo y Francisco de Ávila en los siguientes términos:

Il est probable que, lorsqu'en 1608 Avila se renseigne sur les croyances locales, il organise une enquête parmi les chrétiens les plus dévoués de sa paroisse afin de découvrir le vrai caractère des erreur que le Demon a introduit parmi les indiens. Il a, sans doute, été influencé par les recom-

\footnotetext{
${ }^{6}$ El destacado es nuestro.

${ }^{7}$ Encontramos signos de copia en las fojas 39r, 39v, 40r, 44r, 44v, 45r, 46r, 47r, 49r, 50r, 55r, 58r, 60r.
} 
mendations du Lic. Polo de Ondegardo á ceux qui avaient en charge les âmes des Indiens: la meilleure méthode d'éliminer les pratiques diaboliques des fausses religions andines était de se renseigner en profondeur sur les croyances indigènes. Il est intéressant, d'ailleurs, de constater qu'une copie d'extraits du Tratado de Polo, due apparemment á la main d'Avila, se trouve parmi les manuscrits qui accompagnent le texte quechua de Huarochirí.

2) Sin título, fojas 61r a 63v. Presenta escritura de una sola mano.

Manuscrito Huarochirí, fojas 64r a 114r. Es copia ${ }^{8}$.
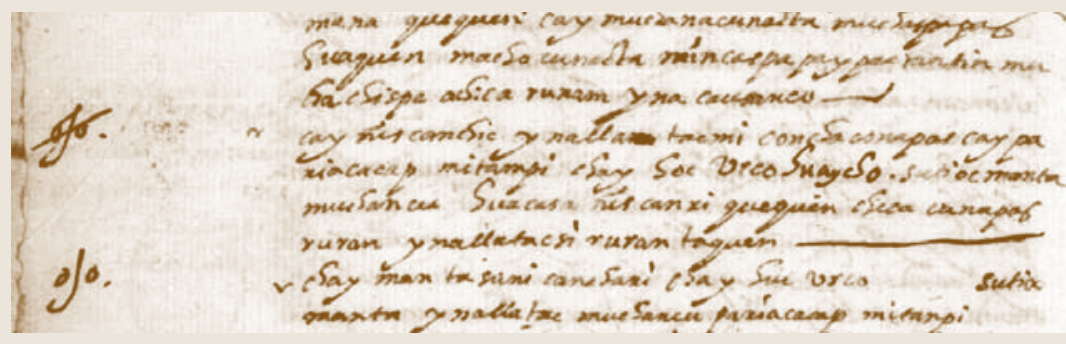

Imagen 3, foja $75 \mathrm{v}$.

Como se puede ver, aparte del espacio en blanco que señala una lectura inconclusa, en el margen izquierdo de la foja aparece escrito dos veces, de la mano de Ávila, la palabra “ojo”, probablemente señalando una corrección. A la misma altura del primer "ojo" -que por lo demás está tachado-, podemos ver la enmienda que realiza al completar el enunciado, añadiendo la palabra huaycho. Tres líneas más abajo, nuevamente el espacio en blanco con la palabra "ojo" en frente. A estas señas de copia se añaden dos posibles enmiendas ya corregidas frente al título del capítulo 14 y del 15.

Gerald Taylor (1987) señala que "el redactor del documento pertenecía a la comunidad de los checa de San Damián; 'ladino', que dominaba irregularmente el castellano y la lengua general, así como también indica que en el texto aparecen elementos de sustrato de otros dialectos quechuas y

${ }^{8}$ Sobre el Manuscrito de Huarochirí, sólo hemos encontrado una marca evidente de copia, en la foja $75 \mathrm{v}$, lo que probablemente se debe a que el manuscrito foliado en el volumen 3169 se encontraba en una etapa avanzada de edición. 
también de un habla aru, probablemente su idioma materno" (1987: 17). Hemos identificado hasta el momento dos manos aparte de la de Ávila que, aunque más que diferenciarse por el ductus de las grafías -notamos algunas diferencias en el ductus de / $\mathrm{j} /, / \mathrm{h} /$ - lo hacen por la disposición, orden y uso del espacio de escritura. Arguedas, por su parte, hacia 1966 señalaba que

No se sabe quién fue el compilador del manuscrito quechua en Huarochirí. No obstante, se conoce el nombre de un mestizo inca que habría colaborado en su composición: Huacha. A pesar de lo incierto de este dato, existe consenso respecto de que el compilador general habría sido alguien de ascendencia andina, probablemente encargado por el padre Francisco de Ávila de documentar las prácticas no cristianas de la región [...] El mestizo Huacha parece haber sido no solo bilingüe sino también bicultural, puesto que establece una comparación muy pertinente entre la cultura oral de los incas y la cultura letrada de los españoles [...] (Arguedas, 2007).

3) Sin título, foja $114 v$, una sola grafía.

Tratado y relación de los errores, falsos dioses, otras supersticiones y ritos diabólicos en que vivian antiguamente los indios de las provincias de Huaracheri, Mama y Chaclla y hoy también viven engañados con gran perdición de sus almas, fojas $115 \mathrm{r}$ a $129 \mathrm{r}$. Es copia9.

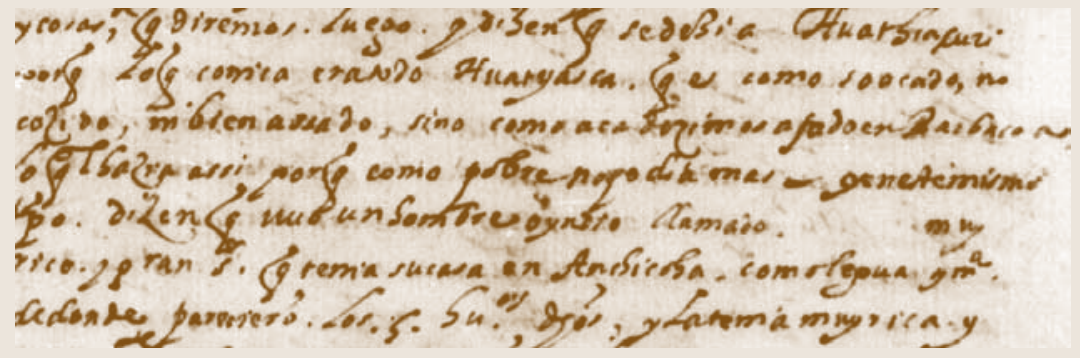

Imagen 4 , foja $122 \mathrm{r}$.

\footnotetext{
${ }^{9}$ Sobre el Tratado y relación de los errores, encontramos marcas de copia en las fojas $122 \mathrm{r}$ y 122v. Ambas palabras omitidas en el Tratado y relación aparecen claramente señaladas en el $M a-$ nuscrito de Huarochirí, y se refieren al nombre de Tutañamca.
} 
Si bien no presenta rúbrica del padre cuzqueño, Jiménez de la Espada señala que es de puño y letra de Âvila (Duviols, 1993: 16). En ninguna parte se adjudica la autoría a Ávila, sino que habría sido "recogido" por el extirpador:

Recogido por el doctor Francisco de Ávila, presbítero (cura de la dotrina de Sanct Damián de la dicha provincia de Huaracheri y vicario de las tres arriba dichas) de personas fidedignas y que con particular diligencia procuraron la verdad de todo, y aun antes que Dios las alumbrasse vivieron en los dichos errores y exercitaron sus ceremonias. Es materia gustosa y muy digna de ser sabida para que se advierta la grande ceguedad en que andan las almas que no tiene lumbre de fee, ni la quieren admitir en sus entendimientos. No se refiere al presente más que la historia, será nuestro Señor servido que el dicho doctor la ylustre y adorne con declamaciones y notas que serán agradables si Dios le diere vida (foja 115r) ${ }^{10}$.

4) Relación de antigüedades deste reyno del Pirú, fojas 131r a 174v. Según Rosario Navarro (2007), tres son las manos que intervienen en este documento: la de Ávila, que hace algunas anotaciones al margen o glosa algunos términos; otras dos que alternan hasta el folio $11 \mathrm{v}$ y luego uno de ellos continúa hasta el final y quien corrige lo escrito por el primero (2007: 15). Así, si fuese la mano de Pachacuti esta última que termina y corrige el documento, no es la que señala, en la primera foja la autoría, por lo que -por lo menos en lo que atañe a aquellas 11 primeras fojas- nos encontraríamos frente a un dictado. No aparecen, en este manuscrito, las mismas evidencias que nos permiten señalar en los otros casos que se trata de copias, sin embargo Duviols ${ }^{11}$, en su edición de la Relación, destaca que:

Estos lazos gráficos entre Ávila y la Relación de Pachacuti nos interesan porque ofrecen una de las escasas pistas que permitan quizás rastrear las huellas del autor de la Relación. El interés surge particularmente del

\footnotetext{
${ }^{10}$ Nos parece que el término "recogido" alude a la relación con el Manuscrito de Huarochirí, nacido de varias informaciones entregadas durante una de sus visitas y que, de alguna manera, ostenta un carácter de transmisión oral (Cf. Martínez, 2008). En este documento, hasta el momento, hemos podido identificar dos manos: la principal que escribe desde el principio hasta la foja $126 \mathrm{r}$ y la que termina el manuscrito. Atendiendo a Jiménez de la Espada, la primera sería de Ávila.

${ }^{11}$ Duviols identifica como anotaciones del extirpador "el título general "Yngas"; en la hoja que antecede a la relación de Molina, donde se lee "Chile año de 1559 fue el primer rebellón de los yndios araucanos"; en la primera página de título de "Relación" de Molina; en la primera página de título "Tratado de un cartapacio"; en la página en la que sólo aparece el título de "Relación de antigüedades dese reyno del Pirú" en la que además de este título se lee de su puño y letra "es notable" y "son quatro quadernos". Insiste Duviols en que, aunque el título de Relación... no está caligrafiado sino escrito a vuela pluma, es de su autoría" (p. 14).
} 
hecho de encontrarse reunidas en los papeles de Ávila la relación de Huarochirí y la de Pachacuti, es decir dos textos que versan sobre creencias y ritos indígenas, sobre "idolatrías", y de haber sido redactados total o parcialmente en lengua indígena por indígenas ${ }^{12}$. Como se sabe que la relación de Huarochirí debió promoverla o encargarla Ávila con miras prácticas, es legítimo preguntarse si la relación de Pachacuti no fue compuesta en circunstancias análogas. Desgraciadamente el examen del manuscrito de Pachacuti -que se ofrece en forma de borrón [borrador] y parece ser original [...] por sí solo no nos autoriza a asimilar las circunstancias de su redacción a las de la relación de Huarochirí (Duviols, 1993: 17-18).

En la Advertencia de la edición de Duviols e Itier, los autores señalan que este manuscrito está firmado por Pachacuti. Sin embargo, la Relación no presenta rúbrica, aunque sí está narrada en primera persona. Hace más de treinta años Duviols propuso que la Relación de Pachacuti no sólo había formado parte de los papeles de Ávila, sino que "el texto fue redactado probablemente a pedido de éste. Sin duda, Ávila apreciaba las virtudes pedagógicas del mito, y está comprobado que lo utilizó en sus sermones de 1648" (Duviols, 1977: 67).

Si bien muchos autores han destacado la múltiple autoría-grafía de los manuscritos del volumen 3169, hemos querido mostrar el hecho de que la gran mayoría son $\operatorname{copias}^{13}$. Lo que nos interesa no es necesariamente la desacreditación de los manuscritos por no ser autógrafos, sino que el hecho de que todos -excepto uno- sean copia estaría indicando no sólo la intención de recuperar las memorias indígenas (o que los españoles recogieron sobre ellos) sino que existía una labor mancomunada y dirigida que dio lugar a la copia de estos textos.

La funcionalidad de la información contenida en este volumen se torna evidente hacia 1648, cuando sale a la luz la obra póstuma de Francisco de Ávila Tratado de los evangelios que nuestra Madre la iglesia propone en todo el año desde la primera dominica de adviento hasta la última missa de Difuntos, Santos de España y añadidos en el nuevo rezado, cuyo segundo tomo corresponde a los sermones de todo el año en lengua índica y castellana, para la enseñanza de indios y extirpación de sus idolatrías.

${ }^{12}$ La Relación de Molina también contiene fragmentos completos en quechua.

${ }^{13}$ Varios son los mecanismos que nos pueden llevar a esta misma conclusión, a pesar de ello, por el momento nos conformamos con aquellos espacios en blanco que evidencian que el copista no pudo leer el original y, reservando un espacio para completarlo después, sigue escribiendo. Como se verá un poco más adelante, en el caso del Manuscrito de Huarochirí podemos verificar este proceso de posterior escritura.

TR A T A DO DE LOS EVANGELIOS QVE NVESTRA MADRE LA IGLESIA PROPONE EN TODO EL ALO DESDE EA PRINERA DOMINICA $D$

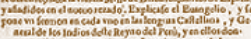

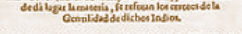
DEDICADO AL SANTISSIMO RREDICA

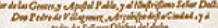
POR EL DOCTOR D. FRANCISCO DAVILA NATVRAL DE LA CIVDAD DEL

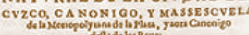
TOMO PRIMERO, SVE CONTISNE DESDE

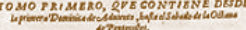




\section{SOBRE FRANCISCO DE ÁVILA. RELACIÓN ENTRE LA EXTIRPACIÓN Y LA ESCRITURA (INDÍGENA)}

Bien siendo el autor intelectual, el recopilador o el copista mismo, hechas las consideraciones anteriores es imposible dejar de lado al estudiar cualquiera de estos manuscritos la figura de Francisco de Ávila.

Según lo señala el mismo padre cuzqueño, al exponer sus méritos y servicios

Soy persona de letras, y que las profeso y me precio de ellas; doctor en cánones por esta Universidad, donde fui graduado, rigurosamente examinado y aprobado, habiendo estudiado siempre con extrema pobreza y no más ayuda que la de Dios, que fue servido alimentarme, y me he ocupado más de trece años en curatos de indios, enseñándoles y doctrinándoles en nuestra santa fe católica. Soy asimismo hijo expuesto de esta tierra, de padres naturales de ésa y nobles, aunque no conocidos; gozo de los privilegios de los que el derecho llama expuestos ${ }^{14}$, quorum parentes ignorantur, $y$, por el consiguiente, soy hábil para cualquier oficio, dignidad, canongía y beneficio, así por derecho como por indulto que concedió la Santidad de Clemente VIII a los tales expuestos, y para mejor cautela y abundancia, tengo particular dispensación en caso que fuese necesario, aunque a lo que he entendido, el ser expuesto es lo que más me había de ayudar, me ha dañado cerca del Cabildo desta iglesia, en la nominación que hizo, si no me puso en buen lugar" (Medina, 1904: 385).

A esta información, Porras Barrenechea añade que Ávila fue un excelente escritor en lengua quechua y que se educó en la compañía jesuita del Cuzco, comenzando su carrera eclesiástica en 1591. Estudió luego Cánones y Leyes en San Marcos de Lima y posteriormente fue nombrado cura de San Damián de Huarochirí.

En la fogosa campaña de su época contra los ritos gentílicos supervivientes Âvila se especializó por su ardor en la predicación y en arrebatar a los indios de Huarochirí sus "ídolos, conopas y amuletos". Predicó ardientemente contra los dioses más venerados de la región, los cerros Pariacaca y Chaupiñamca, y al margen de su predicación exaltada hizo

${ }^{14}$ Pierre Duviols, en el estudio biobibliográfico anexado a la (re)edición de Arguedas, señala que probablemente Ávila conocía el apellido de sus padres biológicos, pues al morir dejó como herederas a sus sobrinas Josefa Hermenegilda de la Torre y Catalina de León, quienes se encontraban en el convento de la Encarnación. A pesar de conocer sus orígenes, Ávila los habría silenciado ya que probablemente era mestizo y Toribio de Mogrovejo tenía una seria política contra la ordenanza de mestizos (en: Arguedas, 2007: 215). 
una copiosa vendimia de leyendas sencillas del terruño andino adheridas a la fauna y a la flora con una gracia de fábula primitiva. Paradójicamente este fiero iconoclasta, denunciado por los indios y por Huamán Poma como un extorsionador, y que sobrellevó por ello dos años de cárcel de los que salió absuelto, es el más fiel depositario de las leyendas de la región de Huarochirí, que recogió en memorias e informes en la propia lengua originaria. Su Tratado y relación de los errores, falsos dioses, y otras supersticiones y ritos diabólicos en que vivían antiguamente los indios de las provincias de huarochirí, Mama y chaclla y hoy también viven engañados con gran perdición de sus almas, escrito en 1608 y conservado en la Biblioteca Nacional de Madrid, es un monumento de la lengua quechua $^{15}$. El filólogo italiano Hipólito Galante lo ha reproducido en 1942, en edición facsímil y traducciones quechua, latina y castellana. Ávila publicó, además, en $1646^{16}$, su Tratado de los Evangelios, que es una colección de sermones en lengua índica y castellana, para todo el año y la enseñanza de indios y extirpación de idolatrías. En la introducción a sus sermones, Ávila dicta algunas lecciones útiles sobre fonética y ortografía (Barrenechea, 1999: 228-229).

Antonio de Acosta, en el estudio biográfico presentado en la edición de 1987 del Manuscrito de Huarochirí, da cuenta de lo extraordinario del proceso legal seguido contra Ávila. Dentro de las acusaciones encontramos las recurrentes de índole económica -ya que Ávila había ampliado la cuota de producción indígena-, la apropiación de recursos agropecuarios y las denuncias de carácter sexual ${ }^{17}$.

Este proceso judicial, que afectó la carrera eclesiástica de Ávila, sería el que dio origen para la creación del Manuscrito de Huarochirí y del Tratado y

\footnotetext{
${ }^{15}$ Probablemente sea una errata la confusión en el título, ya que es el Manuscrito de Huarochirí el que está escrito en quechua y no el Tratado. Otra explicación posible es que Porras Barrenechea, considerando que el Tratado y relación era una traducción del Manuscrito de Huarochirí, analogase el título castellano para el texto quechua que no presenta ninguno.

${ }^{16}$ A pesar de que no tenemos este texto a nuestra disposición, la mayoría de los estudios biobibliográficos que hemos consultado señalan la fecha de publicación del tratado de los evangelios en 1648.

17 “Ávila fue denunciado por algunos de los indios de su doctrina ante el Juez Provisor del arzobispado, siendo acusado de distintas actividades que venía practicando y que estaban expresamente prohibidas por el III Concilio. Las acusaciones fueron presentadas a través del Protector de Indios Francisco de Avendaño y este comportamiento difería en principio de la reacción habitual de los indios contra sus curas, que era de acusarlos aprovechando las visitas pastorales. El tomar la iniciativa de dirigirse a Lima parecía suponer una intención más decidida de los indios de actuar contra el doctrinero. Por otra parte, quienes acusaban a Ávila no eran simples indios del común. Eran caciques, indios principales y contadores de distintos ayllus y huarancas de los pueblos de Santiago de Tumna, Santa Ana de Chaucarima y San Francisco los que suscribían hasta cinco listas de capítulos, lo que implicaba un importante despliegue de fuerzas sociales frente al doctrinero de S. Damián" (Acosta en Taylor, 1987: 571-574).
} 
relación. Mientras el cura se encontraba esperando la sentencia de su juicio, decidió que la mejor manera de rehacer su figura era informar a la sociedad colonial acerca de las prácticas religiosas serranas. Sin embargo, en primera instancia fue impedido de llevar a cabo su investigación, ya que se consideró que ésta podría servir más bien para vengarse de los indígenas que para cumplir el objetivo que públicamente señalaba.

Aun así, el celo con el que Ávila llevó a cabo su misión extirpadora tuvo distintos matices según el tipo de artefacto o culto frente al cual se encontrara.

Si se esmeró en salvar y fijar el mito indígena que nos ha llegado como el llamado Manuscrito de Huarochirí, es porque, en ausencia de una cultura prehispánica escrita y de una religión elevada, la palabra no podía ser erigida en objeto de adoración y no representaba un peligro. Pero, con evidencia, esa misma palabra era para él una fuente de primer orden para desenmascarar la idolatría y le daba la posibilidad de establecer un inventario de dioses, huacas, ritos y creencias. No escapaba a su celo el hecho de que, a través de objetos y gestos, podían subsistir elementos antiguos, demoníacos, ocultos en prácticas ambiguas. Sin embargo, la cristianización no podía ser solo destrucción, sino que también tenía que ser construcción; y la mejor manera de asentar un verdadero cristianismo de los indios venía a ser la palabra, único complemento positivo y necesario a la de los ídolos (Arguedas, 2007: VIII-IX).

Desde esta perspectiva, la palabra indígena "extirpada" y su escritura representan para Ávila un avance en su misión evangelizadora ya que, al plasmar en el papel los cultos idolátricos de las provincias que visitaba, por una parte dejaba constancia de ellos y por otra creaba un registro que no sólo sería práctico para otros misioneros o extirpadores, sino también para propósitos ulteriores, como la publicación de su Tratado de los evangelios en 1648. Así, la acumulación de distintos testimonios (como los que presentan los manuscritos foliados en el volumen estudiado) otorgados por diferentes sujetos enunciantes (Polo de Ondegardo, Pachacuti Yamqui, Cristóbal de Molina, etc.) a lo largo de varios años, es un muestrario interesante tanto de los logros de la empresa extirpadora y evangelizadora así como también de sus fracasos. En esta perspectiva, el que los indígenas escribieran tampoco representaba un peligro en términos de la divulgación de cultos, ya que la gran mayoría de los nativos no sabía ni leer ni escribir.

\section{¿TALLERES DE ESCRITURA?}

Ahora bien, con respecto a la posibilidad de que Ávila hubiese tenido la idea de un taller de escritura, consideramos que las evidencias textuales ya 
señaladas en el presente artículo son suficientes para concluir varios puntos:

1) Francisco de Ávila intervino en todos ellos, ya sea escribiendo el título, glosándolo o determinando su estructura narrativa, como sucede con Manuscrito de Huarochirí y Tratado y relación.

2) Francisco de Ávila copiaba los títulos, al menos gran parte de ellos, y los escribas copiaban el cuerpo del capítulo ${ }^{18}$.

3) En todos ellos participaron al menos dos escribas o "manos".

4) La temática "creencias y ritos indígenas" es transversal a todos ellos.

5) Sabemos que el Tratado y relación es una reformulación comentada de Manuscrito de Huarochirí cuyo objetivo era ser publicado.

Ahora bien, pensar que este tipo de prácticas fuese exclusivo u originario de la época colonial y territorio americano, sería un error. Tanto en occidente como en el terruño americano existen varios antecedentes que plantearían una continuidad de este tipo de talleres hacia la Colonia.

Los talleres de escritura de la Edad Media serían un antecedente a este tipo de práctica. Para Glenisson, luego de la fundación del Imperio Romano y las invasiones bárbaras del siglo $\mathrm{V}$, ocurre una mutación en la producción de libros, pues su producción deja de estar en mano de los librarii y pasan a ser parte de las funciones de centros eclesiásticos que no tienen por objetivo el comercio de libros sino la realización de obras necesarias para la comunidad. Se trata de una actividad esencialmente desinteresada -al menos en cuanto a los bienes de este mundo-incluida en el total de tareas que debía cumplir el monje...

En réponse à ces besoins furent créés les scriptoria, ateliers de copie attachés à un monastère ou à une église cathédrale. Trop rares sont les sources nous renseignant sur l'organisation des scriptoria ecclésiastiques: les cas du monastère Saint-Gall -un plan établi vers 830 indique l'emplacement de son scriptorium- reste exceptionnel. Toute la chaîne de production est assurée à l'intérieur même de l'établissement, de la préparation du parchemin -fourni souvent par les troupeaux du monastère-, à la reliure, en pasant, bien sûr, par la copie et la décoration.

La copie même du texte est généralement un travail d'équipe, réalisé sous la direction d'un chef d'atelier. Un manuscrit peut être copié par un seul et même scribe ou bien par un équipe de copistes qui se partagent

\footnotetext{
${ }^{18}$ Esta manera de formar a los escribas parece bastante lógica. La supervisión constante del padre cuzqueño se debía, en parte, a que la mayor parte de estos manuscritos estaban escritos en dos lenguas no estabilizadas totalmente: el quechua y el español (con su variante español andino). La profusa glosación de todos los manuscritos revela una minuciosa preocupación de Ávila.
} 
le travail, en général de cahiers: un changement d'écriture, de "main", permet alors de déterminer le nombre de copistes ayant participé á l'entreprise [...] Dirigé par le responsable de l'atelier, le travail du scribe, bien souvent sujet á des distractions ou recru de fatigue, est revu par des correcteurs intervenant au besoin, parfois d'une encre différente, qui dans les marges, qui dans l'interligne (Glenisson, 1988: 40-41).

Comparando la descripción entregada por Glenisson y la caracterización sobre las prácticas escriturarias de Ávila, encontramos coincidencias varias. Sin embargo, Ávila no es el único en dar cuerpo a esta actividad en la América colonial. Duviols (en Arguedas, 2007: 234) indica que

El padre Barraza escribía que Ávila "escogió entonces a algunos indios buenos cristianos, temerosos de Dios, y con ellos andaba por los pueblos inquiriendo, descubriendo y desbaratando huacas y adoratorios", y esto antes de pedir ayuda al rector de la Compañía, es decir, antes de junio de 1609; también Huamán Poma de Ayala desempeñó semejante papel al servicio del visitador de idolatrías Cristóbal de Albornoz durante su campaña contra el Taki Onkoy. Es muy posible que don Juan de Santacruz Pachacuti -cuyo manuscrito viene en el mismo volumen, y está anotado por Ávila- se encontrase en una situación parecida.

Navarro Gala, con respecto a la Relación de Pachacuti, señala que era frecuente que los indios principales tuviesen escribanos o secretarios a su servicio, así como indígenas que se dedicaban a las labores administrativas, mientras que

Por otra parte estaban los sacerdotes, quienes, además de tener como ayudantes a indios, parece que animaban a éstos a hacerse escribanos; el padre Jerónimo Mendieta así nos lo cuenta: "Y los religiosos les ayudaron harto a salir escribanos, porque los ocupaban a la continua en escribir libros y tratados que componían o trasuntaban de latíno romanza en sus lenguas de ellos". De modo que si existieron pequeños talleres en los que algunos indígenas eran iniciados en el arte de la escritura como mera copia, a la manera relatada por el padre Mendieta o Motolinía, no es difícil suponer un mayor grado de autonomía por parte de algunos indios principales -recuérdese Huamán Poma- que, tal vez siguiendo las sugerencias de los sacerdotes españoles, contribuyeran voluntariamente a la difusión de la religión católica (Navarro, 2007: 16-17).

Por otra parte, Ossio comenta sobre el caso de Martín de Murúa:

1590, La Merced, Cusco. Virreinato del Perú. El padre Martín de Murúa, mercedario y encomendero, apura en su taller la redacción de un ma- 
nuscrito que contará a las autoridades toledanas la verdadera historia de los incas, en colaboración con su adoctrinado Guamán Poma de Ayala y un grupo de amanuenses ${ }^{19}$. Sus informantes son miembros de la realeza inca, vinculados a determinadas parroquias del Cusco. Su objetivo es contar la vida de los soberanos incas y sus coyas, desde Manco Cápac hasta Túpac Amaru, el último inca de Vilcabamba, ejecutado por órdenes del virrey Toledo, así como las acciones de los míticos capitanes de los ejércitos imperiales (Paredes, 2008).

El mismo autor señala que algunas de las características del taller de Murúa eran el uso de borradores y la colaboración de indígenas. Uno de ellos, Guamán Poma, habría tenido también un taller artesanal:

Lo dicho hasta el momento sugiere que, así como [Murúa] saqueó a otros cronistas de origen europeo, Murúa no tuvo el más mínimo inconveniente en hacer lo mismo con Guamán Poma y el personal de su taller artesanal. La diferencia en este caso es que posiblemente se hizo con conocimiento del cronista indio, pues los testimonios sobre este sacerdote en la Nueva corónica dan cuenta de que se conocieron y que sus vínculos no debieron ser esporádicos. Lo más probable es que este sacerdote contrató los servicios del indígena, cuyas habilidades en el manejo de castellano, de la escritura y, probablemente, del arte pictórico no le pasaron desapercibidas (Ossio, 1998).

Rolena Adorno señala, comentando el método de producción de la Nueva corónica de Guamán Poma de Ayala, que es posible seguir las hipótesis de Ossio con respecto a que Guamán Poma $^{20}$ se habría valido de un equipo familiar para llevar a cabo su labor, mientras que, en cuanto a la prosa de la Nueva corónica, Cárdenas Bunsen (2001: 70-71, 75, 92-98) propone "que la obra es en gran parte responsabilidad de uno o varios amanuenses. $\mathrm{Su}$ análisis es lingüístico; compara las obras transcritas con el texto redactado y también estudia los tipos grafémicos empleados. Identifica tres tipos

\footnotetext{
${ }^{19}$ Según Juan Ossio (2005: 1), "la complejidad que encierra dicho manuscrito, por esconder distintos estilos caligráficos, pictóricos y diferentes etapas de redacción, requiere de muchos ojos para comprenderlo".

${ }^{20}$ Recordemos que Guamán Poma ya había participado previamente en la campaña iniciada por Cristóbal de Albornoz, cuyas prácticas escriturarias parecen tener cierta relevancia en este contexto de estudio. Según Urbano y Duviols, Albornoz "también alude a los Memoriales; es decir, a los papeles y documentos de su archivo particular, los cuales podían incluir tanto sus apuntes personales como textos ajenos, versando sobre los ritos y creencias, pasados o presentes, de los indígenas. Según declara él mismo al final, la Instrucción es un extracto de aquellos memoriales. Es, pues, un compendio elaborado en base a otros informes más detallados" (Urbano y Duviols, 1989: 138). Una hipótesis plausible, entonces, es que Guamán Poma hubiese aprendido estas prácticas y técnicas -o bien, las hubiese reforzado- en su estadía con Albornoz.
}

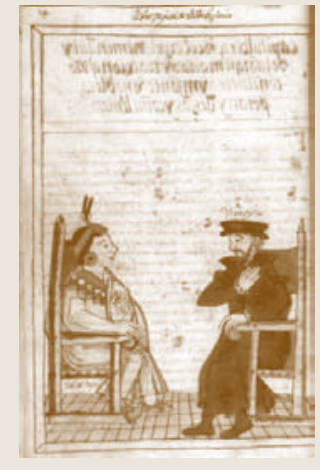




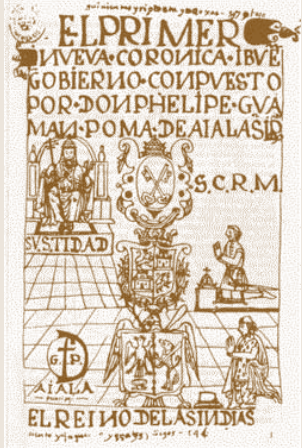

distintos", de los cuales sólo el tercero -autor de las más de ciento veinte enmiendas a pie de página- sería Guamán Poma.

Con respecto a letra e imagen en la Nueva corónica, veo esta opción tan plausible como imposible de probar definitivamente sin encontrar evidencias claras que apuntan a otras personas. Plausible, sin embargo, porque en la Nueva corónica se habla siempre de que su autor tenía alrededor suyo varios "discípulos", leamos ayudantes, a quienes enseñaba a leer y escribir. Pensar en el modo de producción del libro manuscrito es, en todo caso, valioso, no sólo en sí sino que sirve para repensar también el carácter potencialmente colectivo de las obras cronísticas en general. (Cynthia Stone [1999], por ejemplo, ha avanzado mucho el estudio de la Relación de Michoacán descubriendo y analizando su composición colectiva por frailes e indígenas eruditos del pueblo purépecha en los años 1520) (Adorno, 1999).

De la misma manera, parece sugerente la referencia que Juan de Betanzos recoge en Suma y narración de los incas cuando se refiere al culto a las momias de Viracocha Inca, lo cual no sólo refuerza la especialización de los distintos camayocs con respecto a sus funciones, sino también la de su organización y vivienda. Si bien la forma no necesariamente es la de un taller, nos parece que debe ser considerada como un antecedente:

Para lo cual mandó e señaló que tuviesen cada uno de estos [los bultos momificados de Viracocha inca] un mayordomo de los tales sirvientes que ansí le señaló que ansí mismo mandó a estos mayordomos e a cada uno por sí que luego hiciesen cantares los cuales cantasen estas mamaconas y yanaconas con los lores de los hechos de cada uno destos señores en sus días ansí hizo los cuales cantares ordinariamente todo tiempo que fiestas hubiese cantasen cada servicio de aquellos por su orden y concierto comenzando primero el tal cantar e historia e loa los de Mango Capac e que ansí fueron diciendo las tales mamaconas e servicio como los señores habían sucedido hasta allí y que aquella fuese la orden que se tuviese desde allí adelante para que de aquella manera hubiese memoria dellos e sus antigüedades los cuales yanaconas e servicio Ynga Yupangue mandó que tuviesen sus casas e pueblos y estancias en los valles e pueblos en torno de la ciudad del Cuzco e que estos y sus descendientes tuviesen siempre cuidado de servir a aquellos bultos a quien él los había dado y señalado todo lo cual fue ansí hecho desde entonces hasta el día de hoy que lo hacen oculta e secretamente e algunos públicos porque los españoles no entienden lo que es... ${ }^{21}$

${ }^{21}$ Juan de Betanzos (1987: 86), el destacado es nuestro. Siguiendo esta misma línea, es interesante relacionar esta manufactura de la escritura (o de la mantención de la memoria, para el 
Volviendo a la referencia de Rolena Adorno, el considerar la Relación de Michoacán como un texto inscrito dentro de este tipo de prácticas expande la zona geográfica, involucrando también al territorio mesoamericano. Siguiendo su cita, encontramos que Cynthia Stone señala que

All the compilations of indigenous traditions ascribed to the missionaries of sixteenth-century Mexico were collaborative enterprises in wich particular franciscans, dominicans, augustinians, or jesuits involved presided over a more or less numerous group of informants, translators, scribes, and painters. Unlike those missionary activity was focused on central Mexico. However -such as Andrés de Olmos; Torobio de Benavente "Motolinía"; Bernardino de Sahagún; Pedro de los Rïos; Diego Durán; and Juan de Tovar- the friar -compiler of the Relación de Michoacán processed the indigenous customs and beliefs of the region through more than one linguistic and cultural filter: his native castilian and also nahuatl- the language of the spaniards principal indigenous allies (Stone, 1999: 12).

\section{A MODO DE RECAPITULACIÓN}

Numerosos autores han destacado, para cada caso, las características textológicas de los manuscritos compendiados en el volumen 3169 de la Biblioteca Nacional de Madrid. Muchos de ellos han mencionado, también, la relación que el extirpador de idolatrías Francisco de Ávila puede haber tenido o tuvo con la creación de tales documentos. Así mismo, la crítica filológica ha demostrado que la mayor parte de los manuscritos indicados son copia $y$, a la vez, son producto de varios escribientes, algunos de ellos indígenas.

Estas constataciones nos han llevado a plantear la existencia de un determinado tipo de prácticas en las cuales se vio inserta la comunidad indígena, ya sea como informante o como escriba, en la cual un grupo de escribientes -algunos de ellos indígenas- fue dirigido por un religioso con el propósito de crear textos que, por un lado, dieran debida cuenta del estado idolátrico de los virreinatos y, por otro, permitieran al resto de la co-

caso de Betanzos) - como artefacto discursivo- con la fabricación de otros dispositivos como los tejidos cumbis, los keros, los quipus, etc. Es posible que esta regularidad corresponda a los tejedores que realizaban las prendas llamados cumbicamayoc (tejedores de cumbi). Los cumbicamayoc eran tejedores especializados de por vida, reunidos en talleres del estado para la elaboración de cumbi. La producción de estos tejedores estaba destinada a ser distribuida como regalo del inca, siendo ésta la única manera de acceder a este tipo de prendas (MAAM). Museo de Arqueología de Alta Montaña, Salta, Argentina. http://www.maam.org.ar/index.php?seccion=pieza\&seccion2 $=$ enero 2005 
munidad eclesiástica conocer los cultos de las regiones y los ídolos y dioses asociados a cada zona.

Esta práctica se ejerció no sólo en la región andina sino también en el virreinato de Nueva España. Si bien, en cuanto a los manuscritos analizados aquí estas técnicas se vinculan con la presencia de evangelizadores o de extirpadores, existen antecedentes en cuanto a la especialización de determinadas funciones en el ámbito prehispánico que pueden haber colaborado en su institucionalización.

En términos específicamente andino-coloniales, estas prácticas escriturarias se insertarían dentro de una tradición mayor que involucra otros tipos de soportes sobre los cuales no tenemos mayor información en cuanto a su manufactura ${ }^{22}$ y que permitirían abordar modos de organización distintos de los europeos y que habrían modificado las condiciones a tal punto que un nuevo sujeto enunciante se erigió en las instituciones escriturarias: el sujeto andino.

\section{REFERENCIAS}

Acosta, Antonio. 1987. “Estudio biográfico sobre Francisco de Ávila”. En Taylor, G., Ritos y tradiciones de Huarochirí. Lima: Instituto de Estudios Peruanos Instituto Francés de Estudios Andinos, 571-574.

Adorno, Rolena. 1999. "Novedades en el estudio actual de la cronística peruana: Las Casas, Guamán Poma y el padre Oliva”. Disponible en: http://www. fas.harvard.edu/ icop/rolenaadorno.html [Consulta 21.10.10].

Arguedas, José María (trad.). 2007. Dioses y hombres de Huarochiri. Lima: Universidad Antonio Ruiz de Montoya, $2^{\text {a }}$ edición.

Barrenechea, Raúl Porras. 1999. Indagaciones peruanas, Lima: UNMSM.

Betanzos, Juan de. [1551] 1987. Suma y narración de los incas. María del Carmen Martín Rubio (ed.). Madrid: Atlas.

Cárdenas Bunsen, José. 2001. "Notas filológicas para la génesis de la Nueva Corónica y buen gobierno". En: Cantú, Francesca et al. (ed.), Guamán Poma y Blas Valera. Tradición andina e historia colonial. Roma: Antonio Pellicani Editore.

Duviols, Pierre. 1977. La destrucción de las religiones andinas (Conquista y Colonia). Madrid: UNAM.

Duviols, Pierre. 1993. Relación de antigüedades deste Reyno del Pirú. Cusco: Travaux de l'Institut français d'Etudes Andines (74) - Centro de Estudios Regionales Andinos Bartolomé de las Casas.

\footnotetext{
${ }^{22}$ Nos referimos, en este caso, por ejemplo a los vasos pintados de madera, o keros.
} 
Glenisson, Jean. 1988. Le livre au moyen age. Paris: Presses du CNRS.

Martínez, Paula. 2008. "La oralidad como instrumento para acceder al discurso andino colonial. El caso del Manuscrito de Huarochirí”. Diálogo Andino No 32, Arica, Universidad de Tarapacá.

Medina, José Toribio. 1904. La imprenta en Lima. Tomo I (1584-1824). Santiago: Impreso y grabado en casa del autor.

Navarro Gala, Rosario. 2007. Relación de antigüedades deste reyno del Pirú. Madrid-Frankfurt: Iberoamericana-Vervuert.

Ossio, Juan. 1998. “Tras la huella de fray Martín de Murúa”. Disponible en: http://www.fas.harvard.edu/ icop/juanossio.html [Consulta 12.07.10].

Ossio, Juan. 2005. "Polemizando sobre los manuscritos del padre fray Martín de Murúa”. Madrid: Histórica.

Paredes Laos, Jorge. 2008. "El código Murúa. Una historia ilustrada de los Incas” (Entrevista a Juan Ossio). El Comercio. Lima, Perú. 10.08.10. Disponible en: http://elcomercio.pe/edicionimpresa/html/2008-08-10/el-codigomurua.html [Consulta 11.12.09].

Stone, Cynthia. 1999. Mapping Identities: The Relación de Michoacán and the Reappropriation of Indigenous Traditions under Colonial Rule. University of Oklahoma: Norman.

Taylor, Gerald. 1980. Rites et traditions de Huarochiri, Paris: L'Harmattan.

Taylor, Gerald. 1987. Ritos y tradiciones de Huarochirí. Lima: Instituto de Estudios Peruanos - Instituto Francés de Estudios Andinos.

Urbano, Henrique y Pierre Duviols. 1989. Fábulas y mitos de los incas. Historia 16, Madrid. 